\title{
Subsymmetries for the Analysis and Design of Housing Facades
}

\author{
Jin-Ho Park ${ }^{1}$ (iD
}

Published online: 27 October 2017

(C) Kim Williams Books, Turin 2017

\begin{abstract}
With symmetry, complex designs as a whole can be decomposed to several parts for analysis. On the other hand, these parts can be recombined into multiple sequential designs using the same principles. The complementary applications of the symmetry idea are extremely valuable in a constructive sense. This article discusses the seven frieze groups of symmetry and subsymmetry as a compositional device in the analysis and synthesis of building facades. A few housing facades are analyzed with respect to the symmetry and a new façade design in rows of houses, where all seven frieze groups of symmetry are overlaid, is constructed to demonstrate the application of symmetry in a formal composition.
\end{abstract}

Keywords Frieze group · Symmetry and subsymmetry · Façade ·

Architectural design · Compositional device

\section{Introduction}

Symmetry is significant principle in architectural floor plans and elevations (Williams 1999). The symmetry group of a two-dimensional design is either finite or infinite. The finite group of plane symmetry is called the point group. Spatial transformations take place in a fixed point or line. In this category, bilateral symmetry, through which structures, building elements, and rooms are laid out in a mirrored balance along a central axis, dominates the building façade in a classical and modern building.

Subsymmetries arise from a hierarchical and systematic reduction of some symmetry operations; that is, formally selecting particular subgroups of the group of symmetries. The term has been used to denote the spatial correlation between the whole and the component parts in architectural design.

Jin-Ho Park

jinhopark@inha.ac.kr

1 Department of Architecture, Inha University, 100 Inharo, Nam-gu, Incheon 22212, Korea 
For instance, symmetry was a vital principle to Renaissance architects, who revived the Vitruvian tradition. In particular, the use of symmetry as a design principle is particularly evident in the villas of Palladio, such as Villa Emo at Fanzolo, which was designed and constructed during the decade, 1555-1565 (Fig. 1). George Stiny and Bill Mitchell called it "the most conspicuous feature of the Palladio's villa plans (1978:7)." George Hersey and Richard Freedman analyzed Palladian villas and the generation of parametric plans and façades: "Palladio employed [symmetry] with subtlety that is beyond that of his contemporaries" (Hersey and Freedman 1992:15). Symmetry at Palladio's time was viewed as "ideal", such that the design for the building and grounds featured a central axis with mirror-image components on either side. Villa Emo, for example, was

Fig. 1 Andrea Palladio's Villa Emo, plan and elevation follows the rigid bilateral symmetry
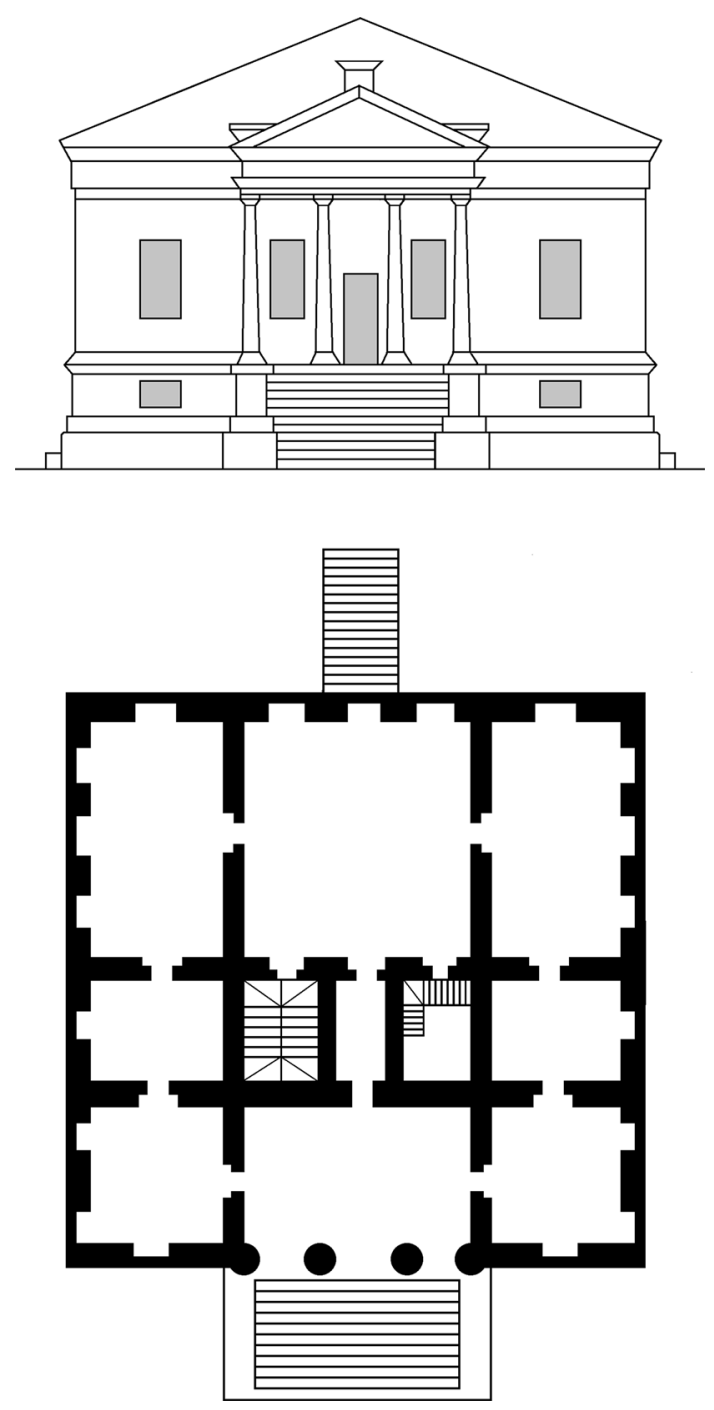
set along a vertical axis in the floor plan and façade. The symmetry of the floor plan is perfectly reflected on the façade with clarity. Accordingly, doors and windows on the façade were arranged accordingly.

The infinite groups are the symmetries of infinite patterns, such as one directional translation of the frieze or two directional translations of the wallpaper patterns. Wallpaper patterns on building façades are abundant in housing site plans and façades of high-rise buildings, in which the translation of identical windows line up in a coordinate plane.

In particular, the point group of symmetry played a double game in the work by Loos and Schindler, marking a decisive break with classical historicism. Loos's Moller house of 1928 illustrates the great contrast between the simplicity of the exterior and the complexity of the interior spaces (Fig. 2).

In the Moller house, although the front façade was freed from the shackles of historical ornament, it nevertheless shows a strong bilateral symmetry. However, this is not reflected in the interior design; the order that organizes the exterior of the building and that of its interiors are totally heterogeneous in terms of symmetry. The symmetric contrast between the plan and façade must have been Loos's intention in the first place. Gravagnuolo wrote that "Symmetry, in this case, is not a tardy adherence to classicism but the taking of a renunciation to an extreme, the extreme that is, of the architectural negation" (Gravagnuolo 1982:194).

The application was reversed in Schindler's Mackey Duplex (Sheine 2001) (Fig. 3). While the floor plan was arranged along an axis, the façade displayed no indication of symmetry. Basically, the symmetry of the floor plan is unexpected from such a façade. This is typical in Schindler's work, where it is hard to predict its spatial forms from the floor plans. The spaces in the interior flow into each room with various levels of sequenced steps, beginning at the entry gate and rising up to the top; on the exterior, simple and rectilinear space-forms are interlocked and interpenetrated. Their union creates a rhythm of complex of combinations, making it impossible to discern the symmetry of the floor plan (Park 1999). Nevertheless, the final floor plan of the duplex is not perfectly bilateral, due to some practical adjustments as well as functional requirement during the design process; however, the initial parti of the plan lies in perfect bilateral symmetry. ${ }^{1}$

What is surprising is that architects have paid so little attention to the use of the seven frieze groups on a building façade, whereas their use in site planning of rows of houses is common. As the term 'frieze' indicates, ${ }^{2}$ the frieze groups of symmetry are found most often in ornamental designs. In architecture, a fine example of using the symmetry in floor plans is Le Corbusier's 1925 worker's housing at Pessac, ${ }^{3}$

\footnotetext{
1 See (Gebhard 1993: Drawing no. 2081).

2 The term, 'frieze' arises from architectural example. The American Heritage Dictionary defines the term as "A plain or decorated horizontal part of an entablature between the architrave and cornice, and "A decorative horizontal band, as along the upper part of a wall in a room".

3 A decorative use of Frank Lloyd Wright's concrete block houses in Los Angeles belongs to this category. There are four concrete block houses, including the Ennis, Freeman, Millard, and Storer houses, in which Frank Lloyd Wright employed his series of concrete textile blocks; see (March and Steadman 1971).
} 
Fig. 2 Adolf Loos, the Moller house of 1928, the front façade is strongly symmetrical but the floor plan shows no symmetry
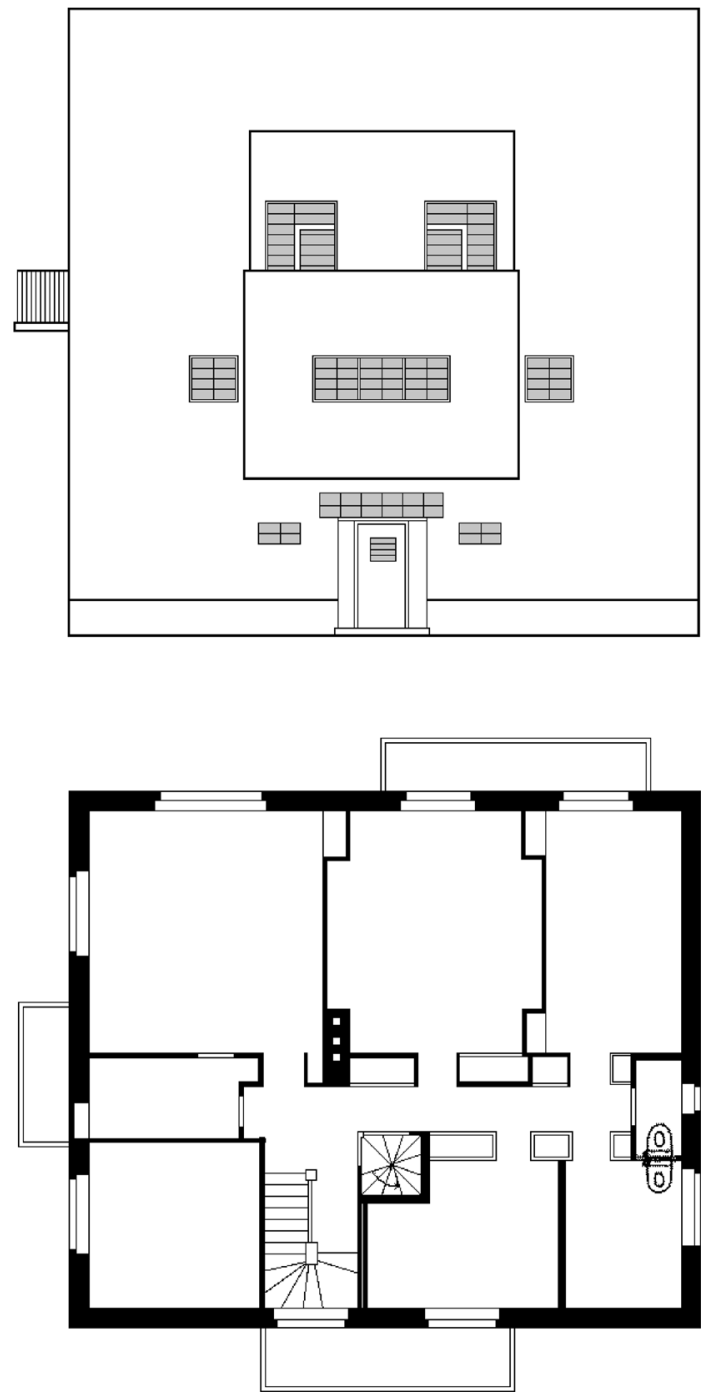

where he exploited all four types of the planar symmetry transformations: reflection, translation, rotation, and glide reflection.

Applications of multiple and hybrid superimpositions of the seven frieze groups on a single façade in a building are rare ${ }^{4}$ in rows of houses or clustered housings (Untermann and Small 1977; Kirschenmann and Muschalek 1980; Gausa 1998).

\footnotetext{
${ }^{4}$ (Park 2000, 2001, 2004) provided a number of analytic examples of architectural floor plans with regard to the point group symmetries. Also, (Cohen 2001) analyzed the façades and plans of the Palazzo Gambara and the Villa Tauro to identify the hybrid use of symmetries. He observed the complexity of the facades in a multiple superimposition of symmetries with architectural elements in three-dimensional 'translucent' space. His approach may lie in Colin Rowe's and Robert Slutzkey's "phenomenal transparency" (Rowe and Slutzkey 1997). Due to unconventional placement and orientation of an internal
} 
Fig. 3 Rudolph M. Schindler, the Mackey Duplex of 1939, the floor plan is subdivided along the bilateral axis, whereas the façade shows two interlocking boxes
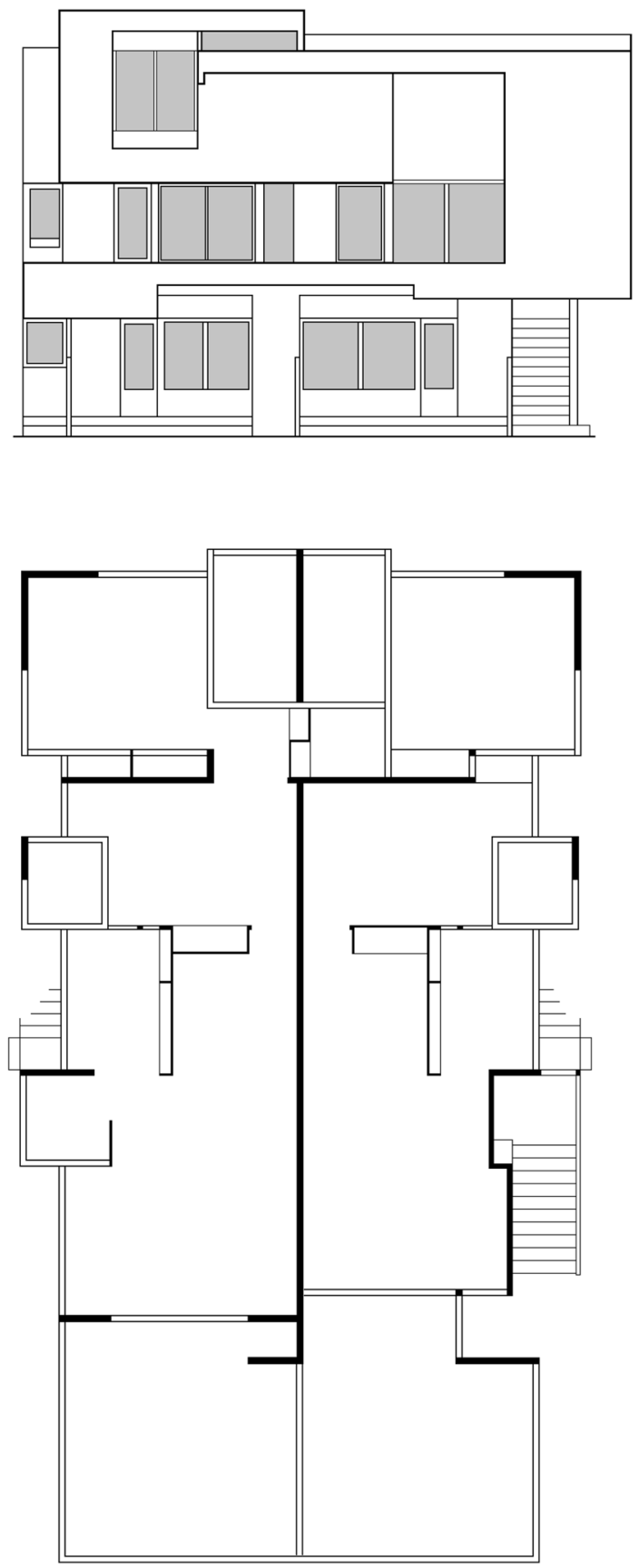

(Footnote 4 continued)

staircase with windows, a different symmetric dynamism on the front as well as the rear façade of the building was created. Cohen's tool analyzing the building facade is based on bilateral symmetry. 
Instead, some sorts of translational repetitions in façade designs are commonly found. Despite their enormous potential when deliberately employed in the design process, the application of superimpositions of frieze groups on building façades has been overlooked. For the most part, the use of symmetry on building façades relies on a singular symmetric operation, such as simple repetition and translation.

In a previous study (Park 2000), I analyzed and synthesized architectural floor plans after reviewing the algebraic structure of the point group symmetry in mathematics. There are good reasons for architects to adopt a mathematical language in discussing the symmetrical designs. Because the language of mathematics is concise, explicit, and systematic, the structural order of the various layers of symmetries can be analyzed exhaustively to interpret the regularity of a pattern, and new designs can then be constructed in terms of its symmetry group. This present study further develops the complementary procedure to study the potential applications to building façades with regard to the seven frieze groups employed. First, the mathematical principle behind the classifications of symmetry groups for frieze patterns is discussed in order to provide a rigorous foundation. Then, architectural façades are analyzed with respect to the symmetry. The remainder of the article applies the principle to the construction of a hypothetical new building façade, developing its abstract three-dimensional computer model.

\section{Seven Frieze Groups}

Briefly, a frieze pattern consists of two-dimensional motifs repeating in one direction only. There are only seven distinct groups that can be the symmetry group of a frieze in an infinite sequence of equidistant points arranged in a horizontal direction (March and Steadman 1971; Shubnikov and Koptsik 1974; Coxeter and Moser 1980; Martin 1982; Grünbaum and Shephard 1987). ${ }^{5}$ Thus, every frieze pattern belongs to one of only seven mathematically possible patterns. Five types of isometries occur in the frieze groups: translation $(\mathrm{T})$, half-turn (S: rotation through $180^{\circ}$ ), vertical reflection $(\mathrm{Rv})$, horizontal reflection $(\mathrm{Rh})$, and glide reflection $(\mathrm{G})$. Different possible combinations of the above isometries form seven distinct symmetry groups together.

The seven frieze groups include the following: Pmm2, Pma2, Pm11, P1m1, P1a1, $\mathrm{P} 112$, and P111. The letter "P" denotes the one-dimensional frieze pattern. The three notations ' $x y z$ ' after ' $\mathrm{P}$ ' denote the direction of the symmetry operations in the frieze. The symbol immediately after ' $\mathrm{P}$ ', ' 1 ' or ' $\mathrm{m}$ ' indicates the presence or absence of a mirror reflection on the axis perpendicular to the translation. Mirror or glide symmetry along the axis of translation is given in the second space to the right of 'P'; the symbol, ' $\mathrm{m}$ ', means that a reflection exists in the axis of translation; ' $\mathrm{a}$ ', means that a glide reflection exists in the axis of a translation while " 1 " indicates the absence of a reflection or glide reflection. The third space to the right of ' $p$ ' is either 1 or 2 ; the presence of a half-turn rotation is indicated by 2 , and the absence

\footnotetext{
5 When two different colors are used, there are seventeen distinct frieze groups; and when three colors are used, there are seven distinct frieze groups (Wieting 1982).
} 
Table 1 Matrix of the symmetry operations in the frieze groups

\begin{tabular}{llll}
\hline Pxyz & No reflection & Reflection & Glide reflection \\
\hline ' $\mathrm{x}$ ' reflection on perpendicular axis to translation & 1 & $\mathrm{~m}$ & \\
' $y$ ' reflection on parallel axis to translation & 1 & $\mathrm{~m}$ & $\mathrm{a}$ \\
' $\mathrm{z}$ ' half-turn 1,2 & & & \\
\hline
\end{tabular}

of a half-turn rotation by 1 . All seven frieze patterns have translational symmetry. Table 1 provides the matrix of the above denotations.

Various planar patterns can be classified with regard to the symmetry group, as can the seven frieze patterns. Consider a motif that is the smallest asymmetric piece of the pattern to be repeated by translation and use it as a stamp along an axis of translation. Different patterns are created along the axis of translation while using the same motif repeatedly. Observations of the patterns show that the subgroup relationship among the groups can be structured hierarchically in an order similar to the point group subsymmetries (Park 2017). Each distinct frieze pattern of the symmetry group and its subgroup relationship is summarized adequately in the lattice diagram (Martin 1982).

Figure 4 shows how a pattern changes when the motif is modified in ways that destroy some of its symmetries. In the top row, there are two frieze groups: Pmm2, which contains a reflection perpendicular and parallel to the translation, and a halfturn rotation, and Pma2, which contains a half-turn and reflections in two mirrors at right angles to it. The frieze groups in the second row each have two motifs in a serial pattern of their symmetry groups: P1m1 has a vertical reflection along the translation axis; Pm11 has a horizontal reflection in the translation axis; P112 has a half-turn rotation in the translation axis; and P1a1 is the only frieze group containing a glide reflection and translation but no reflections. The bottom row is P111 containing only one translation of a motif along the translation axis.

The analysis and classification of frieze designs can be done directly using a set of algorithms or procedures which give a complete description of the pattern types through a series of questions. Any frieze pattern can be classified and identified using a flow chart like a decision tree (Fig. 5).

\section{Analysis: Symmetric Precedents}

A building façade is characterized by the way the building elements are arranged. One can discern its pattern with regard to symmetry. Countless examples of symmetrical façades exist, but they based mostly on bilateral symmetry. Examples of these were discussed earlier in the work of Palladio, Loos and Schindler.

The most frequent applications of the frieze groups on building façades appears in rows of houses, where units with a standardized floor plan are lined up repeatedly along the street. Typically, at least three housing units are joined together and are aligned sequentially and mirrored repeatedly in almost identically divided lots in 


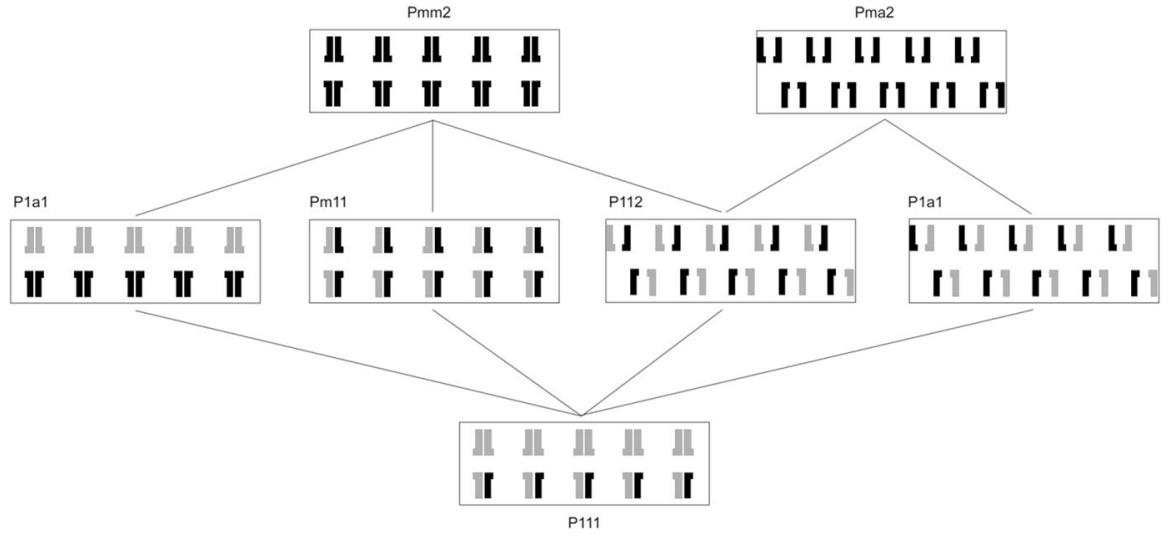

Fig. 4 Seven frieze patterns classified with regard to the frieze groups and the subgroup relationship among the groups

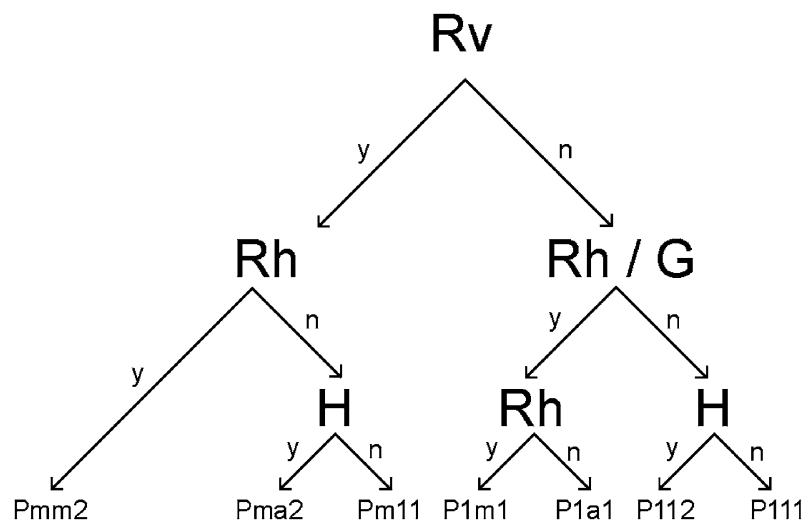

Fig. 5 Flow chart of the frieze group diagram to determine the design $(R v$ vertical reflection, $R h$ horizontal reflection, $G$ glide reflection, and $H$ half turn)

one direction. These housing units are also placed parallel to the street, side by side, to form a uniform street façade.

Although there are many cases that exhibit the ways of deploying frieze symmetry, two housing designs associated with subsymmetries of the frieze groups on the building plan and façade are given in the following. J. J. P. Oud's Weißenhof Siedlung was built on the Killesberg in Stuttgart in 1927 (Fig. 6). Along with seventeen other architects, Oud developed prototype housing for the modern urban dweller. Oud's asymmetric standard unit exhibited a basic cubical box structure without any ornament. A series of cubical structures was translated and aligned repeatedly along an axis line. Oud's earlier experimentation with regard to the symmetry was also found in a terraced-house complex on a beach boulevard in 


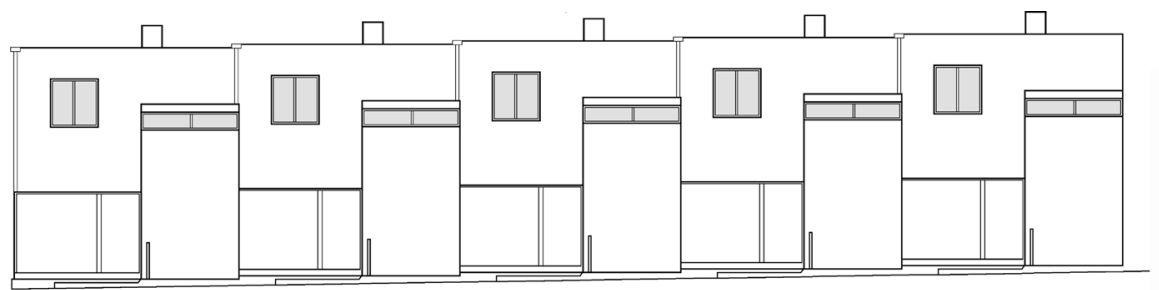

Fig. 6 J. J. P. Oud, Weissenhof Siedlung façade, 1927

1917. The linear pattern of the unit juxtaposition shows a synthetic structure of various boxes interlocked in five stacked layers of backwardly stepped buildings. ${ }^{6}$

Similar approaches can be also found in contemporary housing projects. For example, an elaborated façade design was found in the design of Los Angeles architect Mark Mack, who provided a potential application of the frieze groups of symmetry in a row of house façade designs. The Abbot Kinney Lofts, Venice, California were designed and built in 2006 based on two different types of threestory loft prototypes (Fig. 7). Each loft was paired and reflected on each other along multiple local axes, whereas all eight lofts were arrayed in a row along a central bilateral axis. The façade front and back walls were vividly articulated with different colors and materials, creating an exquisite asymmetrical look in its design. When visiting the site, the façade design looks complicates at the first glance. On the other hand, by reading the façade drawing analytically with the symmetry principle, the symmetry, which is superimposed in overall housing designs, becomes apparent.

In the above examples, subsymmetries of the frieze groups dominate the façade plane without subtle interruption. Oud illustrated a simple and unrelieved repetition of a standard housing unit by translating it along an axis. His design must have been very inventive at that time, contrasting and providing an alternative to the highly decorated architecture of Art Nouveau. Mack introduced the prudent playfulness of local and global bilateral symmetries into the façade, even though he had no formal method or system of composition in his practice. ${ }^{7}$

Various usages of symmetries of the frieze groups on a building façade are found, yet they are mostly repetitive patterns of a standard unit (Hoffmann 1967). The repetitive and standardized building units might be a vital requirement for the effective and economical adoption of mass housing production but their use leads to repetitive and monotonous designs, producing unpopular and unpleasant private residential environments. Instead, the housing façade can be designed to avoid a monotonous or continuous façade.

\footnotetext{
${ }^{6}$ For the symmetrical aspect of Oud's terraced-house complex on a beach boulevard, see (Gunter 1985).

7 In an interview with the author, Mark Mack stated, "I don't have a straight method or a preconceived idea of how I go about ... I would say loose fit to me is more important than a tight methodology" (Park 1996).
} 


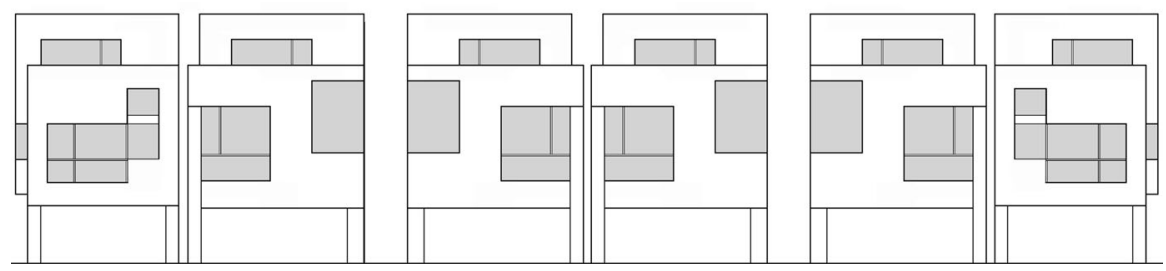

Fig. 7 Mark Mack, Abbot Kinney Lofts, 2006

\section{Synthesis: Combinatorial Possibilities in Building Façades}

The constructive possibility of the symmetry principle is its most salient and novel feature. Earlier examples of Palladio, Oud and Mack illustrate the use of a singular spatial transformation in a building or rows of houses. The question then arises; what if a multiple superimposition of the seven frieze groups of symmetries is used exhaustively in their façades? In what follows we will forth the architectural possibility that various symmetries of the frieze groups can be overlaid in a building façade to generate a variety of probable façade designs. Although hypothetical, the exercise suggests a way to generate a façade dynamically and systematically. The most positive consequence of this exercise might be that the unlimited resources of symmetry can introduce new playfulness, inventiveness, and creativity into the process of designing façades.

Let us now see how a unified compositional principle may result in a variety of possibilities for façade designs. In generating combinations of possible layouts, variations of the symmetry principles employed in the design are created in $2 \mathrm{D}$ and $3 \mathrm{D}$ space. ${ }^{8}$ By using all or just some of the subsymmetry principles, the application results in a huge number of compositional possibilities.

This idea can be applied to generate a housing façade in the speculative site of a city. Figure 8 presents an urban block that is subdivided into eight equal lots each measuring $20 \mathrm{ft} \times 115 \mathrm{ft}$. On each lot is a standardized unit with a yard in the back and space for parking in the front (no floor plans are shown as this study only deals with the façade).

A composite band of row house façades is then produced, where the frieze groups regulate the underlying geometry as an aesthetical code, giving the façade as a whole a varied appearance. The houses are limited to eight units each residing on the street lot. Two standard units can reside in a single building in which case they can stack on top of each other.

Here the building elements constitute the motifs that will form the overall pattern. We consider a finite series of these elements, which include doors, windows, balconies, recesses, stairs, etc., to create a row house façade. Multiple layers of these elements will be aligned and superimposed on top of each other with respect to the seven frieze groups, forming a globally asymmetric façade. The

\footnotetext{
8 Athanassios Economou (2006) provides an interesting discussion with regard to the translational symmetry in $3 \mathrm{D}$ frieze pattern.
} 


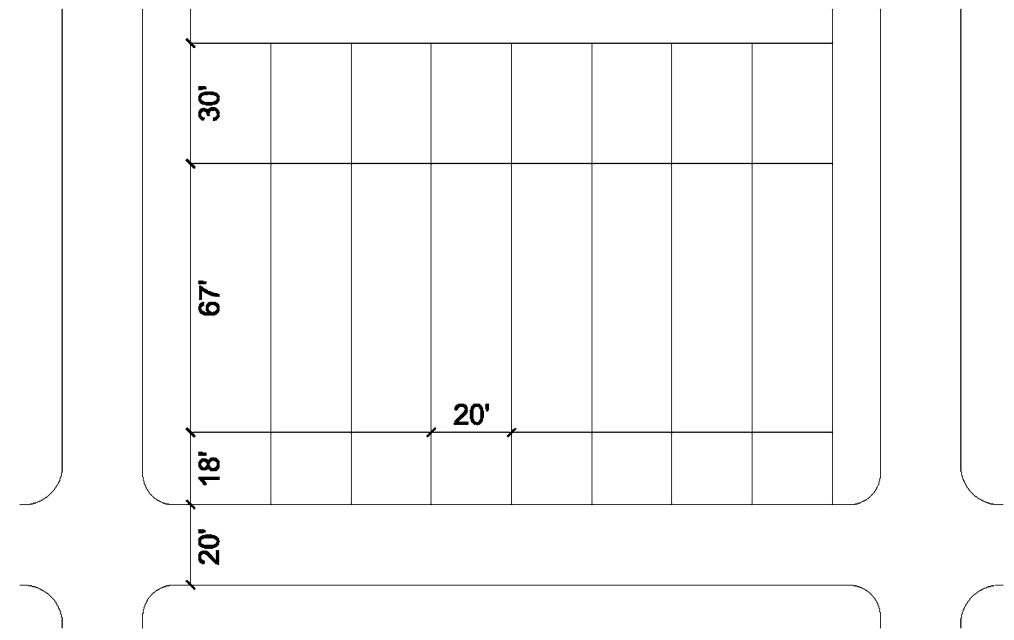

Fig. 8 Hypothetical lot for typical row houses along the street

façade is constructed in such a way that the elements associated with respect to the symmetry coincide.

Figure 9 presents a series of diagrams, in which one of these corresponding building elements are arrayed with respect to the frieze groups. In Fig. 9a, the pattern is shown rooted at the successive translation of asymmetric motifs by a distance: a wall and a stair. Figure $9 \mathrm{~b}$ portrays a pattern of flower boxes. This example illustrates where a window is translated in the line of axis and then mirrored to generate the pattern. Paired, with corner elements, windows establish a rhythm across the units. In Fig. 9c, a gutter and a lanai handrail are mirrored with a subsequent translation. Figure 9d isolates the door and aligns it along a glide reflection. Here again, a decorative lighting element is attached to remove the symmetry of the door rectangle. The motifs in Fig. 9e are paired in a half turn. This forms a partial wall boundary of a unit of row houses. Figure $9 f$ presents a window motif in Fig. 9b that is mirrored in a half-turn and reflected in an axis line. In Fig. 9g, a wall is half-turned and reflected in two mirrors at right angles. This forms the boundary configuration of all eight row house units. All the above generates a unique pattern in forming a façade of rows of houses.

In Fig. 10, starting from the major building walls, doors, stairs, windows, and other elements are aligned and inserted in line with a strict principle, completing a façade design. Proper positioning of each symmetric element produces an orderly superimposed pattern of seven distinct symmetry operations. When overlaid together, separate building elements dissolve in a façade, having no meaning as separate rules of their juxtaposition in the entire façade, and making each underlying layer invisible. When rendered, each element and its underlying principle are embedded within the fabric of the entire façade. Its asymmetrical design does not reveal its underlying geometry; its identity forms a unique pattern.

One of the practical consequences in constructing a hypothetical façade may be a polemic about whether the type of theoretical work can be applicable in three- 


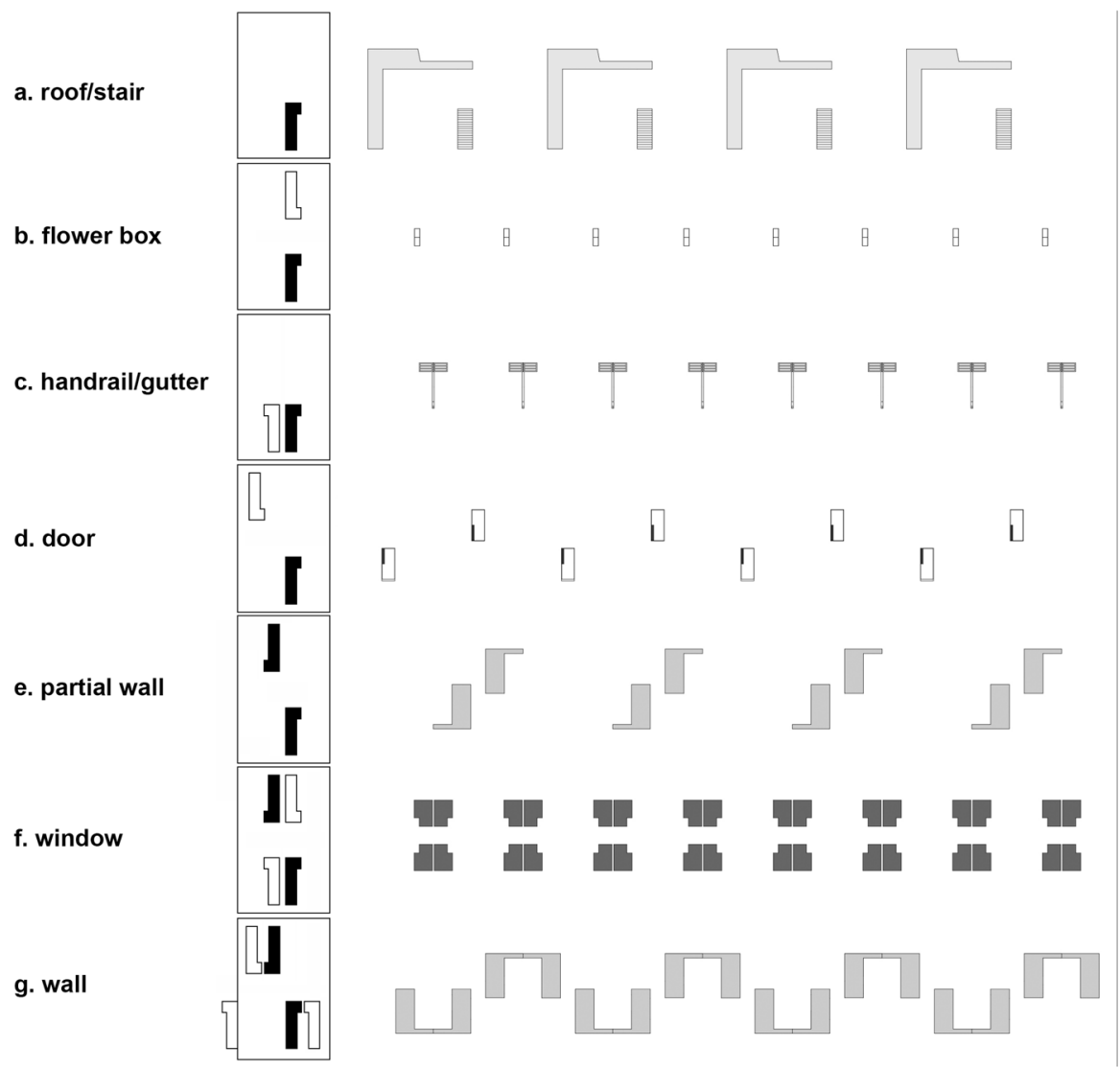

Fig. 9 Seven frieze groups with design elements: a detailed example of how the complete set of frieze groups is used to design the façade

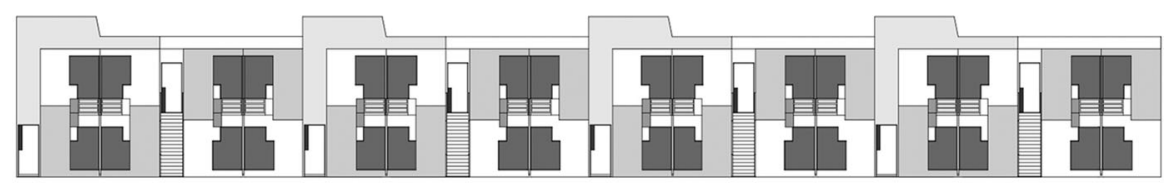

Fig. 10 Final design where all elements are superimposed to form a housing façade

dimensional architectural design. A three-dimensional hypothetical model was fabricated to test the façade in the townscape. Here, form follows façade. The advances in computer technology make it possible to depict the two-dimensional façade design in three-dimensional space. When constructed in a three-dimensional façade design, the layout provides a dynamic look and aesthetic variety in the street perspective, as shown in Fig. 11.

The final façade might be relatively uncluttered but despite its methodical lucidity, it is surprisingly ambiguous in its unexpected consequence. This is a 
striking feature of using the method where the final design creates a synergistic pattern that can hardly discern its underlying geometric coherence. This shows no sign of using 'monotonous' symmetry.

In the design process, using different types of architectural elements with some or all of the seven frieze groups can achieve a distinctive character. The application results in enormous design possibilities. Simply put, a wide range of new and varied designs can be generated depending on the choice of design elements in different symmetric orders.

Depending on how different parts of elements are superimposed on the façade, the expression of the final design will be different, even though it may look as if various elements are permutated, shifted, and positioned. When combined with different colors and materials, dynamic views of the alternating the façades are created. In addition, the unique combination of positive and negative space along the street will also produce dynamic optical effects. In the process of design application, a class of combined multiple façade can be also produced. Each assembly may lead to unique combinations of the elements. In addition, a few elements may be removed, or a few subsymmetry principles left unused, thereby destroying the overall symmetry of the façade. This by no means is without symmetry but it acts as an underlying principle. Furthermore, following the façade design, dynamic floor plans can be produced.

Figure 12 presents four derivations generated using the same principle. The units have their own roofs and are separated by a firewall. The first model of these (Fig. 12a) is a row of houses, where each unit has a clerestory window. The exterior stair is removed and the front door for each row house is placed on the ground level. The pattern for the slightly projecting wall is also changed. In this model, the Pma2 and Pla1 subsymmetries of the frieze groups are removed.

In the second model (Fig. 12b), the projecting wall pattern is removed and the exterior stair is relocated. Two units are stacked together so that the two units appear to be a single building. In this model, the Pma2 and P112 subsymmetries of the frieze groups are removed.

In the third model (Fig. 12c) each unit has its own roof but the forms reflect each other horizontally. The front door is relocated and the exterior stair is removed. In this model, the P1a1 and P111 subsymmetries of the frieze groups are removed.

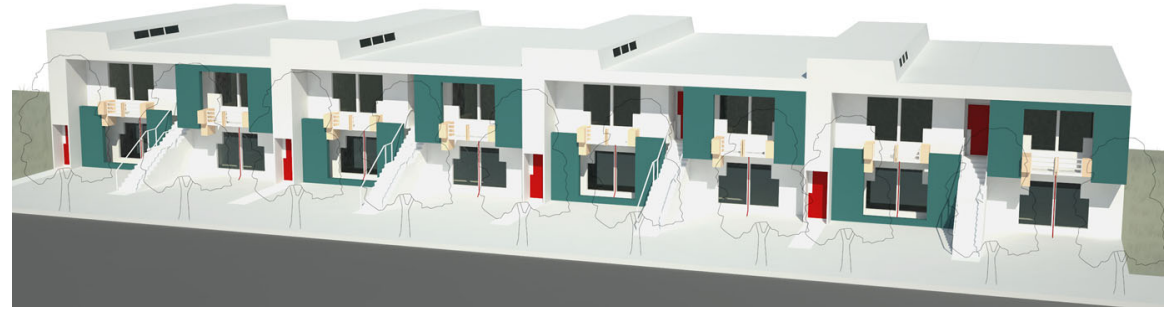

Fig. 11 Three-dimensional computer model is depicted on a streetscape 

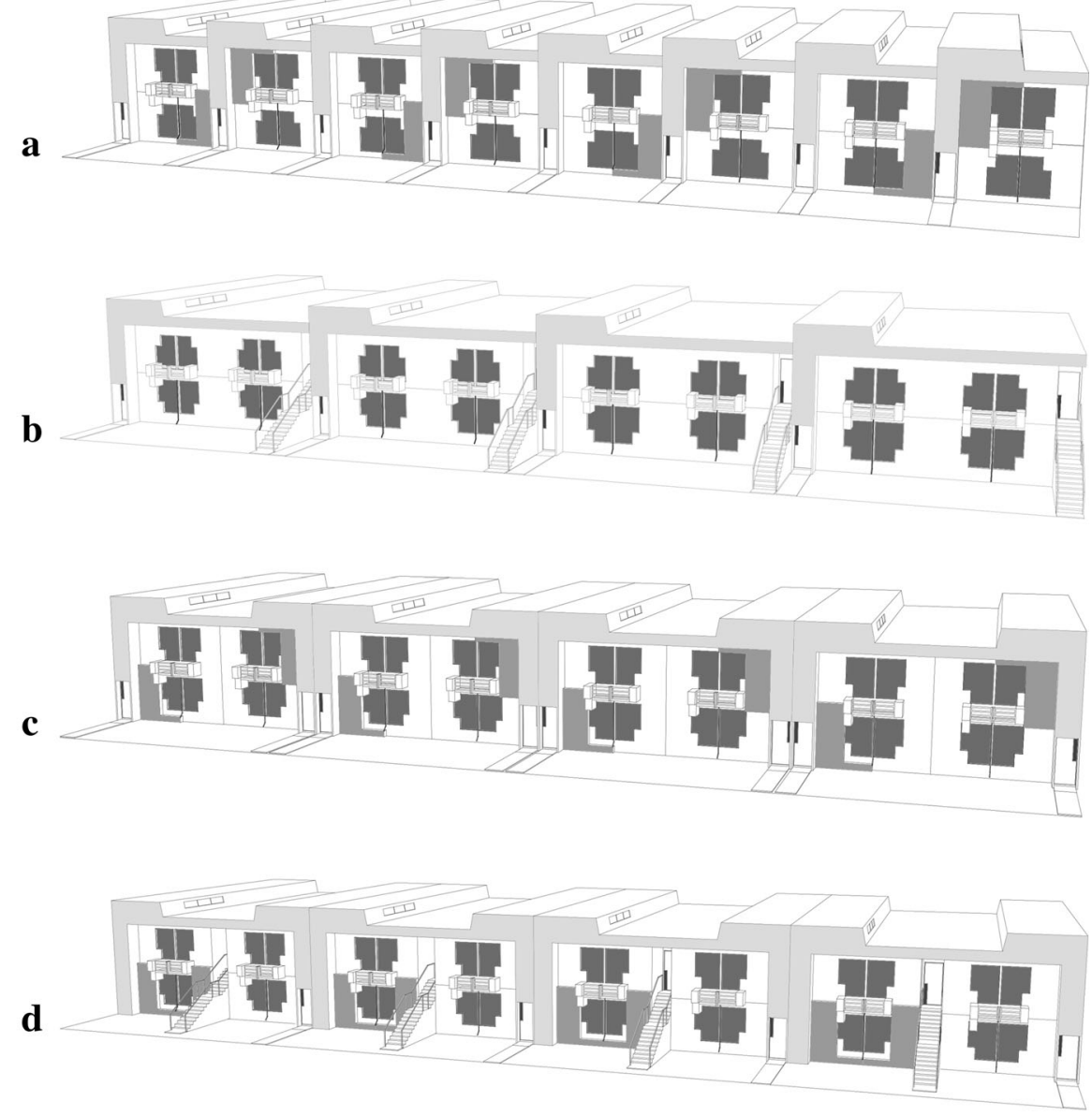

Fig. 12 Four possible façade designs in that a few elements are removed or a few subsymmetry principles are not used. Although they appear similar, they are different from the ways that the principles are applied

The fourth model (Fig. 12d) removes the projecting wall of the upper floor. The roof form is reflected and the exterior stair is translated. In this model, the Pma2, P112, and P111 subsymmetries of the frieze groups are removed.

Rather than superimposing the complete set frieze groups in a single façade, these alternatives show what happens when some of the subsymmetries are not used and a few design elements are removed and relocated. The three designs shown in Fig. 12 would certainly form a family with the earlier design in Fig. 11. These alternative designs show that by using more complex elements or by combining different frieze groups of subsymmetries, a much wider range of dynamic results can emerge. 


\section{Conclusion}

The mathematical notion of symmetry is a useful tool for both the analysis of existing buildings and the design of new ones. Here, a hypothetical building façade has been constructed through the applications of symmetry. Despite its highly symmetrical operations employed in an ordered manner, the symmetric overlay in the final façade is not evident at first sight. Strictly speaking, there is no overall symmetry in the design, but many local symmetries are manifested. One might therefore ask whether this asymmetric façade design is more appropriately defined as "not-symmetric" or "lacking in symmetry", or is instead a design "full of symmetry".

By superimposing all symmetric building elements in various layers, the building's symmetrical façade appears to be destroyed. On the other hand, symmetry in the façade is retained as an underlying principle, strengthening the building's dynamism and achieving with the intricate asymmetric building façade. That is the beauty of the employment of a symmetrical overlay.

This experiment leads to the conclusion that the seven frieze groups of symmetry create a new possibility in producing a variety of dynamic building façades. By combining a set of different design elements with the symmetry principle, a variety of designs can be further generated. When a series of row houses are designed and combined as such, the street façade of the pedestrian level can become more elaborate, providing a dynamic townscape. Above all, when color is used on the façade, the complexity and the number of probable designs increase dramatically (Düttmann et al. 1981).

Acknowledgements This work was supported by an Inha University research grant. Most of all, I am grateful to Professor Lionel March for his support and advice during the preparation of this manuscript. I also thank Kim Williams for reading and editing the final manuscript.

\section{References}

Cohen, Preston Scott. 2001. Contested Symmetries and Other Predicaments in Architecture. New York: Princeton Architectural Press.

Coxeter, Harold S.M and W. O. J. Moser. 1980. Generators and Relations for Discrete Groups. New York: Springer Verlag.

Düttmann, Martina, Friedrich Schmuck and Johannes Uhl. 1981. Color in Townscape. San Francisco: W. H. Freeman.

Economou, Athanassios. 2006. Tracing Axes of Growth. Pp. 351-365 in: Visual Thought: The Depictive Space of Perception (Advances in Consciousness Research 67), Liliana Albertazzi, ed. Amsterdam: John Benjamins.

Gausa Manuel. 1998. Housing-New Alternatives, New Systems, Barcelona: Actar Publishers.

Gebhard, David, ed. 1993. The Architectural Drawings of R.M. Schindler. Garland Architectural Archives. New York: Garland Pub.

Gravagnuolo, Benedetto. 1982. Adolf Loos: Theory and Works. New York: Rizzoli.

Grünbaum, Branko and Shephard G.C. 1987. Tilings and Pattern. New York: W.H. Freeman.

Gunter, Roland. 1985. Balance: De Stijl and the Tradition of Dutch Urban Culture. Daidalos 15: 83-93.

Hersey, George and Richard Freedman. 1992. Possible Palladian Villas. Cambridge: MIT Press.

Hoffmann, Hubert. 1967. Row Houses and Cluster houses: An International Survey. New York and Washington: Frederick A. Praeger. 
Kirschenmann, Jorg and Christian Muschalek. 1980. Residential Districts. New York: Whitney Library of Design.

March, Lionel and Philip Steadman. 1971. The Geometry of Environment. Cambridge: MIT Press.

Martin, George. 1982. Transformation Geometry: An Introduction to Symmetry. New York: Springer.

Park, Jin-Ho. 1996. An Interview with Mark Mack. In a periodical, POAR(People of Architecture). Seoul: Ganhyang.

Park, Jin-Ho. 1999. The architecture of Rudolph Michael Schindler (1887-1952): The formal analysis of unbuilt work. Unpublished Ph.D. dissertation, University of California, Los Angeles.

Park, Jin-Ho. 2000. Subsymmetry Analysis of Architectural Designs: Some Examples. Environment and Planning B: Planning and Design 27(1): 121-136.

Park, Jin-Ho. 2001. Analysis and Synthesis in Architectural Designs: A Study in Symmetry. Nexus Network Journal 3(1): 85-97.

Park, Jin-Ho. 2004. Symmetry and Subsymmetry as Characteristic of Form-making: The Schindler Shelter. Journal of Architectural and Planning Research 21(1): 24-37.

Park, Jin-Ho. 2017. Frieze Symmetry as an Underlying Principle of Housing Elevation Designs. Pp 49-57 in: Morphological Analysis of Cultural DNA: Tools for Decoding Culture-Embedded Forms, JiHyun Lee, ed. KAIST Research Series. Singapore: Springer.

Rowe, Colin and Robert Slutzky. 1997. Transparency. Basel and Boston: Birkhäuser.

Shubnikov, A. V. and V. A. Koptsik. 1974. Symmetry in Science and Art. New York: Plenum Press.

Sheine, Judith. 2001. R. M. Schindler. New York: Phaidon Press.

Stiny, George and William Mitchell. 1978. The Palladian Grammar. Environment and Planning B 5(1): 5-18.

Untermann Richard and Robert Small. 1977. Site Planning for Cluster Housing. New York: van Nostrand Reinhold.

Wieting, Thomas W. 1982. The Mathematical Theory of Chromatic Plane Ornaments. New York: Marcel Dekker.

Williams, Kim. 1999. Symmetry in Architecture. Visual Mathematics 1(1), http://members.tripod.com/ vismath/kim/index.html. Accessed 27 Sept 2017

Jin-Ho Park teaches architectural design, theory, and history as a professor in the Department of Architecture at Inha University, Korea. Prior to joining Inha University, he taught in the School of Architecture at the University of Hawaii at Manoa, USA as an associate professor with tenure. He earned his Ph.D. in architecture from University of California, Los Angeles (UCLA). His research has been published in various referred journals, nationally and internationally. Currently, he serves as an editorial member of Open House International. His recent book publications include "Graft in Architecture: Recreating Spaces" (Images Publishing, 2013), "Designing the Ecocity-in-the-Sky" (Images Publishing, 2014). 